\title{
Materials for Writing - Was This the Case of the Runaway Bandwagon?
}

\author{
Kristi Nuraini \\ Universitas Muhammadiyah Jember \\ (kristinuraini@yahoo.com)
}

\begin{abstract}
The teaching of language has developed from time to time. Writing as one of the skills in language learning has also gone through different concerns; starting from less concerned in the Audio Lingual Method (ALM), becoming to have more concerned in the Communicative Approach of Language Teaching (CALT). The materials also differ for the focus of language learning are different; from forms or structure focused into meaning or communicative focus; from controlled activities into more natural and communicative ones. This paper will cover the teaching of writing, techniques of gathering ideas for writing and the influences of methodologies in writing tasks.
\end{abstract}

Keywords: teaching of writing, Audio Lingual Method, Communicative Approach in Language Teaching, methodologies in writing tasks

L1 Writing is one of the productive skills in language learning; one needs to be able to produce written expression using the target language he learned. It takes a lot of effort and practices to be able to write well. For language learners, writing is considered to be a big burden because not everyone possesses the ability to draw their ideas into a good order. Moreover, what they believed about teaching writing is a matter of editing their students' works. Materials produced were mainly for the purpose of testing rather than teaching. This phenomenon, of course, does not support the teaching and learning of writing; what has been available is only a model of good writing. Yet, this does not tell us how to have the good ones. What steps required to have a good writing product have never been taken as considerations.

In most parts of Asia where the book with model essays was a vital learning tool; this was a good model for students. Most of the students memorize the essays but the more sensible ones, they adapted them by studying the patterns of good essays, common ways in which the content was generated and organized or ordered. Such attempt to have a good writing, however, needs a lot of effort.

In late 1960s the Revolution in the Teaching of Writing took place (Hairston, 1982); the Process Approach has changed the teaching of writing from Product to Process. This approach is a very learner-centered approach, which encouraged learning through discovery, the process approach involved learners in gathering ideas through prewriting tasks. This approach engaged learners in cognitive process that they would require in writing. They need to jot down their ideas to be written for their writing activities. They will need to brainstorm any ideas related to the topics. There was a controversy whether there should be a teacher or not to help the students with their writing. Peter Elbow (1973) suggested that teachers should stand out from their students to let them write. Elbow contends 
there is "a place where there is learning but no teaching." It is possible to learn something and not be taught. It is possible to be a student and not have a teacher. Teachers are more useful when it is clearer that they are not necessary. The role of the teacher is to be useful; it is not the teachers' role to provide instructions and directions but to help the student do in a more well-spoken and powerful way what she is already fully capable of doing. He added, in speaking, we use language less consciously than when we write. Indeed, we are suspicious of a person, in ordinary circumstances, who seems to be carefully monitoring the words they use when they speak. We may consciously edit by choosing carefully our words, when we try to be diplomatic, or talk with an interviewer for a job, even when we are angry and know that serious consequences may follow from what we say. But notice the difference, Elbow says, in the way we are so accustomed to speaking freely and then when we sit down to write we become cautious and guarded. Elbow argues that we can free up our writing and get more energy and "voice" into it by writing more the way we speak and trying to avoid the heavy overlay of editing in our initial efforts to write. It means that teachers need to be there among the students to help them learning but not to tell them that the teachers are more capable than the students. Teachers are to be there to give assistance, not a burden by editing every single word that the students are writing. Students need to be give some time to think and have their ideas flow and run freely through their writing. In addition, Reid (1993) writes that "reflection is a process of reviewing an experience of practice in order to describe, analyze, evaluate and so inform learning about practice." It means that students need some time to reflect what they have written and to re-read it, analyze and find any necessary corrections for improvement. There is another belief proposed that says students should not be given absolute freedom when doing the writing. These cognitivists believe that teachers could intervene to provide help for learners by assisting them to generate or rearrange their ideas. Teachers, in this context, are as the assistance rather than controller; they are there only when necessary, they are not supposed to be interfering with whatever the students trying to put into their writing, instead, they give more hands when the students are somewhat misguided when organizing their ideas.

This controversy, however, does not come up with solution of having a good book for teaching writing; a book which provides a clear guidance and materials to be taken into the teaching of writing to the students. Therefore, researchers who worked on the reading-writing collaboration then suggested ways in which content and audience awareness must lead the way, especially in tertiary level writing. There was a need for academic readers (writing books which had selection of readings for pre-writing) during this time. This combination of reading-writing will definitely help beginner writing to have a model for their writing tasks.

\section{The Teaching of Writing}

Different contexts of the teaching of writing; first, where the public school system adopted methodologies with a very restricted writing component; another is where schools allowed learners to adopt curriculums that prepared students for international entrance or placement examination, usually in the form of preparation books. These two distinct contexts will also have a quite distinct ways of preparing the materials for the teaching of writing to the students, for those are having different purpose of learning the writing skills. Some approaches also influence the teaching of writing. One of the approaches is Audio Lingual Method; this method influences the schools with the structuralist syllabus. It emphasizes the learners to be orally proficient; the focus is therefore less in writing. It treats writing only as a supporting skill, and copying of dialogues through repetitive drills becomes the major parts of the practices. Another common practice is the transformation drills which usually restrict the students to rewriting a number of statements 
in negative or interrogative forms.

The ALM and structuralists syllabus allow teachers to have more realistic expectations of their teaching goals. The syllabus helps the teachers in the writing component by providing guidelines. The tasks which are recommended are those supporting the ALM and the structural syllabus. Some of these tasks are controlled writing, free writing, and guided writing, which are easily found in the textbooks used in the teaching and learning process. Dialogues which present the oral practice can then be presented as the writing tasks; where students need to pay attention on the punctuations and mechanics things of the sentences in the dialogue, such as punctuations, capitalization, etc. The same text can also be used to have guided writing and free writing activities. Dictation also becomes a part of writing task which includes memorization to complete it. The last is called dicto-comp, in which teacher will read sentences and students will need to write based on their understanding of what they have heard from what the teacher said rather than their memorization.

Communicative Approach to Language Teaching in 1970s has brought a sense of utilitarianism and consumerism to teaching a language and this was largely connected to reality and authenticity. People need to communicate and therefore they need to have a lot of exposure to cues or stimuli. In CALT, the stimuli largely came from authentic materials and inspiration of this come from daily life. Authenticity from the perspective of materials brought a greater sense of reality in communication. In communicating their ideas in written, people need also to have the real or authentic model of writing. This has expanded the writing genres from routine deliverance of essay topic and the timed writing into fun activities in the classroom and learners began writing in a number of new genres, mainly those related to media and advertising. These genres require a lot of creativity and imagination; here learners move away from regularly working on five-paragraph essays to redesigning cereal boxes and writing advertisements for their new products. These require other skills authenticity of media to work on. The use of the authentic materials and media writing (which linked writing in classrooms to the writing for the market, reallife use of writing product), brought about an awareness of the importance of creativity and deeper understanding of audience demands. Knowing these two will lead the writer to have ideas to draw on their writing. The results can be of course far different from the common essay writing, since the purpose and also audiences are different as well. Expanded genres in writing indeed arouse learners' creativity in writing, for each genre has its own features to be emphasized. Moreover, genre writing relates more to the real-life; it makes the genre writing becomes more applicable and readable for the audience. Therefore it must be encouraged by providing more chances for learners to perform or do more in developing their writing ability.

As students prepare to write, they need to think about the purpose of their writing: Are they writing to entertain, to inform, or to persuade? Setting the purpose for writing is just as important as setting the purpose for reading, because purpose influences decisions students make about form. One of the most important considerations is the genre or form the writing will take: a story, a letter, a poem, or an essay. A writing activity could be handled in any one of these ways. Students learn to use a variety of writing genres; through reading and writing, students become knowledgeable about these genres and structures (Donovan \& Smolkin, 2002).

In the applicable curriculum in Indonesia, at least there are six genres to be taught to and mastered by students across levels, such as descriptive, narrative, recount, expository, journals, and letters. Each of them brings its own purpose, therefore assuring each of their purposes is important. Further consideration is, due to its different nature, each genre requires different language features 
as well as organization of ideas in composing the piece of writing. Prior to producing this piece of writing, what matters most is simply to start writing.

\section{Techniques of Gathering Ideas in Writing Free Writing}

Peter Elbow (1973) proposed the idea of free writing. He stated that the most effective way to improve your writing is to do freewriting exercises regularly, at least three times a week. They are sometimes called "automatic writing," "babbling," or "jabbering" exercises. The idea is simply to write for ten minutes (later on, perhaps fifteen or twenty). Keep going, quickly without rushing. Never stop to look back, to cross something out, to wonder how to spell something, to wonder what word or thought to use, or to think about what you are doing. If you can't think of a word or a spelling, just use a squiggle or else write "I can't think what to say, I can't think what to say" as many times as you want; or repeat the last word you wrote over and over again; or anything else. The only requirement is that you never stop. What happens to a free-writing exercise is important. It must be a piece of writing which, even if someone else reads it, send no any ripples back to you. It is like writing something and putting it in a bottle in the sea. Free-writings help you by providing no feedback at all.

Free-writing may seem crazy but actually it makes simple sense. Unlike speaking, writing has the advantage of permitting more editing, although it is its downfall too. Almost everyone interposes a massive and complicated series of editing between the time the words start to be born into consciousness and when they finally come of the end of the pencil or typewriter onto the page. This is partly because schooling makes us obsessed with the "mistakes" we make in writing. Many people constantly think about spelling and grammar as they try to write. They also think about the awkwardness, wordiness, and general mushiness of their natural verbal product as they try to write down words. Yet, these are not just "mistakes" or "bad writing" we edit as we write. We also edit unacceptable thoughts and feelings, as we do in speaking.

Unlike speaking, when writing there is more chance to think of what is right. This chance, however, is a terrible burden. Editing, on the other hand, does not really matter. It is usually necessary for giving a more satisfactory ending. The problem is that editing goes on at the same time as producing. The main thing about free-writing is that it is non-editing. It is an exercise in bringing together the process of producing words and putting them down on the page. Practiced regularly, it undoes the ingrained habit of editing at the same time you are trying to produce. It will make writing less blocked because words will come more easily. There is a lesson here for writing: trying to get the beginning just right is a formula for failure - and probably a secret tactic to make writing seems hard.

Elbow (1973) introduced techniques for free-writing, including looping. Looping involves writing freely for a short time, reading and selecting the center of gravity sentence as the most important idea, then using it as the topic of other pieces, which are also written freely by the learners. Doing this way, the learners learn to develop gradually what they have written to be continued in the following period of lesson. Unfortunately, this technique may not always result in neat and cohesive paragraphs; redundancies, inaccuracies and disorganized ideas to be tolerated and do not have to be monitored or corrected by teacher. Indeed, the teacher has to be more responsive rather than authoritative (Murray, 1985). Teacher is to give suggestions not to give judgement on the learners writing, assists the learners rather than tells what they have to do. Here, the learners are given freedom to write their ideas, once they have done some parts they can discuss with the teacher about their writing; and teacher is again, to give suggestion or hints to the learners based on what they have done. 
The opposite belief comes from cognitive school of thought, proposing strategies for teachers to teach learners writers. Prewriting preparation becomes the focus of writing instruction. They come with new strategies for initiating writing like cubing, clustering and mind maps. They call them as the idea-generators or idea-organizers. They believe that heuristics has a major role in the invention process of writing. Even strategies used by journalists to organize their thoughts and writing (journalistic questions) were adopted by school as "thinking tools' for learner writers. Journalistic questions help learners invent ideas. They include questions that journalist often use as they seek to elicit form their target subjects. Nolasco (1993) gets the students to answer the following questions to write about agriculture in their country:

1. Is food grown on large farms or small farms? 2. How much work is done by hand?

3. Are animals or machines used to plough the fields?

4. Is farm work done by men or women?

5 . Is the soil rich or poor?

6 . Which crops or fruits are exported?

7. What food is imported?

Adopted from Nolasco (1993, p. 43)

Those questions will give background knowledge for the learners to start writing about the topic. They will find completing such a task more practical then when they are faced with a prompt directing to write about agriculture in their country.

Mind maps and other techniques like cubing and clustering could feature writing workbooks, especially for beginner writers who would need some scaffolding techniques to help them build cubes and clusters and mind maps of probable content. These techniques help the beginner writers to start gathering their ideas before they start writing. By doing do the beginner writer can list any ideas related to the topic or content they want to write about; later they will develop the ideas into their writing.
There are four processes of writing first draft, free writing, mind mapping, brain storming, or listing and outlines to both develop topic and get started.

\section{Focused Free-writing}

1. Use a blank paper or computer screen and set a time limit of 5 - 15 minutes

2. Summarize the topic in a phrase or sentence; generate a free flow of thought

3. Write anything that comes to mind, whether on topic or off, for the period of time you chose, 4. Work quickly without pausing, stopping, and rushing

5. Review comes after finishing what to be written

6. At the end, refer back to the beginning: Rephrase the initial topic

Repeat a word, phrase, or important thought or emotion that makes sense.

7. Review:

are there words or ideas to be grabbed onto for the topic?

Is there a main idea to this sequence of ideas?

\section{Listing and Outlines}

This is a more structured and sequential overview of the research to date. Outlining to organizing topics may be necessary to be built from free writing, brainstorming, or mind mapping.

1. Arrange items or topics, usually without punctuation or complete sentences.

2. List topics and phrases them in a grammatically similar or parallel structure (subjects, verbs, etc.).

3. Sequence topics in importance, defining what "level" of importance they are. Items of equal importance are at the same level.

\section{Brainstorming}

1. Use a blank paper or computer screen and set a time limit of 5 - 15 minutes

2. Summarize the topic in a phrase or sentence; generate a free flow of thought

3. Write down everything that comes to mind to generate a free flow of thought: 
a. Think of any ideas related to this topic

b. Make up questions and answers about the topic, no matter how strange

4. Review:

are there words or ideas to be grabbed onto for the topic?

Is there a main idea within this sequence of ideas?

\section{Mind Mapping}

1. Think in terms of key words or symbols that represent ideas and words

2. Take a pencil and a blank piece of paper or use a blackboard and chalk

3. Write down the most important word or short phrase or symbol in the center. Write other important words outside the circle. Draw over-lapping circles to connect items, or use arrows to connect them. Leave white space to grow your map for; (a) further development, (b) explanations, and (c) action items.

4. Work quickly without analyzing

5. Edit this first phase. Think about the relation of outside items to the center, erase and replace and shorten words for these key ideas. Relocate important items closer to each other for better organization. Use color to organize information. Finally, link concepts with words to clarify the relationship.

6. Continue working outward. Freely and quickly add other key words and ideas

Think weird: tape pages together to expand the map; break boundaries. Develop in directions the topic it takes. As the map expanded, tend to become more specific or detailed.

\section{Cubing}

Cubing is a writing exercise used as a pre-writing technique. Cubing, forcing a writer to think and re-think a topic, allows a writer to explore various aspects of that topic. We all know that a cube has six sides. Understanding from the picture of a cube; to discuss it is important to discuss each side of the object. Therefore, it is necessary to change perspectives in order to examine and write about the cube's six faces. This exercise challenges every writer to examine various perspectives of an object or idea. The following is the guideline for students.

1. Choose a small, three-dimensional object. Choose a geometric object, not a round oneobject would not be appropriate for this exercise.

2. Place the object in front and write for two minutes about what is seen.

3. When the time is up, turn the object a little and write for two minutes about that side of the object.

4. Next write about the underside. Keep turning the object until all the six aspects (or sides) of it are written.

5. Be fairly strict with time-keeping.

6. Discover as much as possible about the object.

In cubing, a writer is demanded to probe a topic from six different perspectives. First, select a topic (issue, person, idea, event, problem, person, object, scene) and write it at the top of the page to help keep it firmly in mind. In three to five minutes, write from each of the perspectives listed below. Start from what is familiar, identify those areas that will need further thought or research and speculate about where this information will be discovered. Keep going until you have written all six perspectives. As in free-writing, it is important to reread. The following are the six perspectives which are vital in this technique. 1. Describing: Physically describe the topic; about the look, color, shape, texture, size, etc. 2. Comparing: How is the topic similar to or different from other topics

3. Associating: What other topic/thing that can be associated to this topic?

4. Analyzing: Look at the topic's components. How are these parts related? How is it put together? Where did it come from? Where is it going?

5. Applying: What can be done with the topic? What uses does it have?

6. Arguing: What arguments be made for or against the topic? 


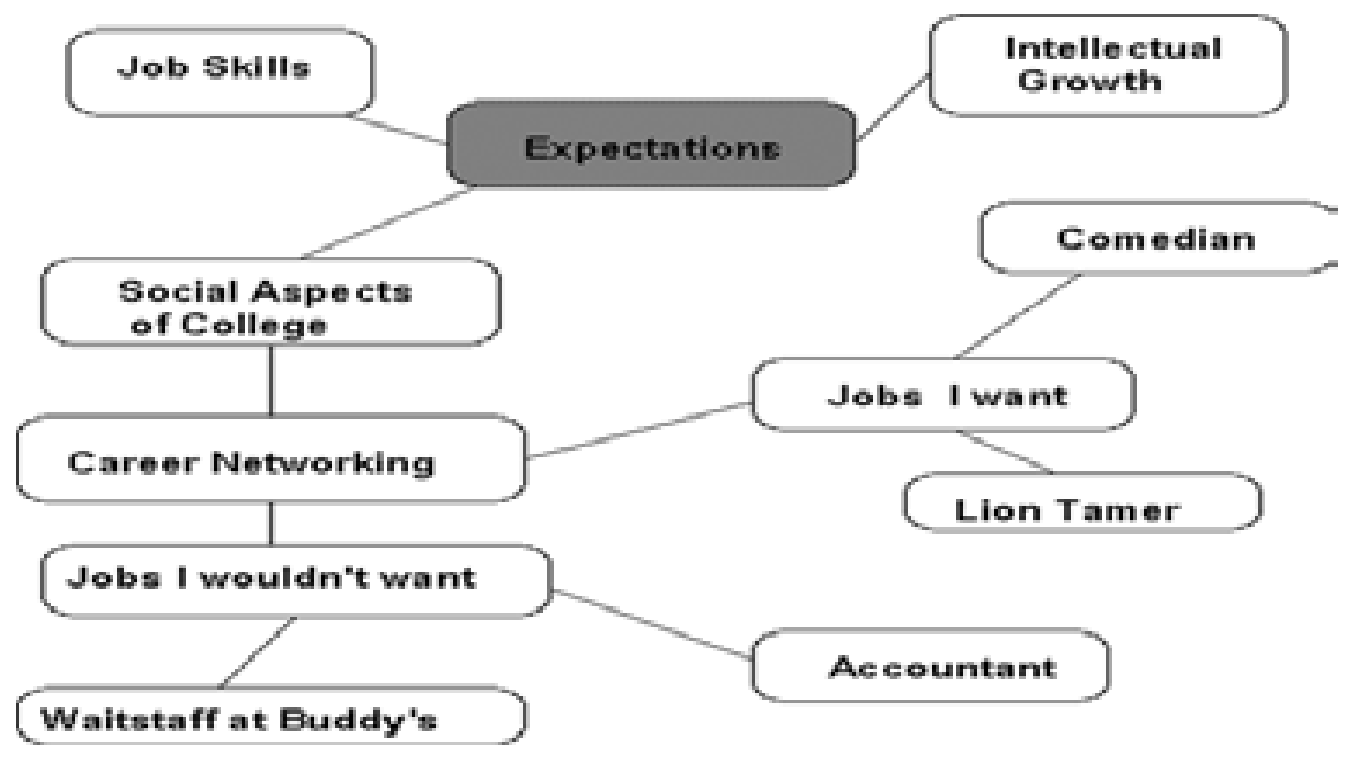

Figure 1. Clustering exercise

However, as it applies to every technique as well, cubing has its own pros and cons. First, cubing is an excellent tool for rapidly exploring a topic. It reveals quickly what is known and unknown, and it may alert the writer to decide to narrow or expand the topic. For the cons, cubing asks us to examine a topic in an unusual way and this may prove frustrating to some writers. It may feel awkward at first to describe something like abortion and this may cause a writer to abandon this technique or, worse, the topic itself.

\section{Clustering}

Clustering is a type of prewriting that allows the writer to explore many ideas as soon as they occur. Like brainstorming or free associating, clustering makes possible to begin without clear ideas.

To begin to cluster, choose a word that is central to the assignment. For example, if the paper to be written is about the value of a college education, the word "expectations" might be chosen, and this should be written in the middle of the sheet of paper. Circle expectations," then write words all around it --words that occur when thinking about "expectations." Write quickly, circling each word, grouping words around the central word and connecting these new words to previous ones with lines. Once the words are exhausted, go back to the central word and begin again. For example, "expectations" might lead to "the social aspects of college," which may lead to "career networking." When this line of association is followed, it might lead to words that compare the types of jobs. Some words will seem to be dead-ends; while some others seem to be related one to another. In other words, random associations eventually become patterns of logic. After looking over such clustering exercise above, it can be concluded that the writing may be about an exciting career as a performer of some type rather than a job in the service sector or behind a desk. The exercise would look like Figure 1.

Clustering does not take the place of a linear, traditional outline; but, as the example shows, it allows ideas exploration before committing them to a particular order. In addition to providing support for the learners to invent and organize ideas, an activity like the previous example can provide key words that the learners need to write about the topic. This activity helps the learners to choose which ones are related to the topic and which ones are not. Besides, it also helps them limit their scope of discussion in their writing later on. 


\section{The Influence of Some ELT Methodologies on Writing Tasks}

There are two English Language ELT methodologies that have played vital roles in the development of materials for teaching ESL writing; Audio Lingual Method (ALM) and Communicative Approach in Language Teaching (CALT). In 1960s where ALM played its role, it regarded writing only as a way to help learners to speak better. In other words, writing was treated as minor important compared to the speaking, or oral proficiency in learning a language. ALM goes with the sructuralists approach in which they believe that language is a system that can be learned by mastering its rules. Writing materials, therefore, sought to reinforce the language structures or forms that the students had just learned. Additionally, the ALM was based on the theory of behaviourism. The behaviourists believe that errors are as bad as habits which could become fossilized if they are not corrected immediately, so in speech, repetition lead to persisting and correct use, in writing memorization of texts and dictation reinforce the language taught.

The Audio Lingual Method supports the writing materials to be controlled writing tasks. The examples of common writing tasks in ALM are:

a. Sentence transformation (e.g. changing active to passive voice, positive to interrogative and negative)

b. Making sentences from a list of words

c. Arranging jumble sentences into the correct order to organize a paragraph

d. Substituting words (e.g. 'we' to 'he')

e. Sentence completion

It is obvious that the Audio Lingual Method focuses the writing activities strictly controlled in the items that focused on accurate formal language usage. The items of the tasks are focused on forms rather than meaning or content of the language. It is called as formsfocused rather than meaning-focused and emphasized accuracy over fluency of language (Nation, 2009). These kinds of activities are also found in the writing materials, such as sentence completion where there is a paragraph with some blank spaces which must be completed with the appropriate tenses of the given words in the brackets.

In the 1980s Communicative Approach in Language Teaching appeared with an emphasis on learning language in meaningful context. Language is learned in a real context of the language use, not the usage. It is no longer forms-focused but it is rather meaningfocused; not to mention in writing as well. The writing is based on the actual use of the language. This led to the actual use of authentic materials like newspapers and excerpts of text form real life context, which could elicit more purposeful and original written works from the learners. Information gap and negotiation of meaning activities emerged to encourage meaningful communication in the language classroom. The activities can be in the form of classroom survey, observation or interviews to get a data needed for the writing a simple reports on the students hobbies or habits. In a negotiation for meaning activity, for example, the students are put into groups and each of the groups are given a newspaper ads on renting an apartment. They work in group to decide which unit of apartment they would prefer to rent. Later, they are assigned to write a letter to the owner of the apartment to make an appointment to see the unit. Before completing the task, they can ask the other students within the group to check their work and make a comment about it. These activities promote more learner-centered approach in which students are actively involved in practicing the use of the language to negotiate meaning and communicate ideas. The central attention is on the meaning of the language use, not on the forms or structure of the language use in the real communication setting. CALT helps learners to be more independent in deciding what they have to do to achieve the goal of learning; also in writing, they can choose their own ways of how they would start their writing and how they would gather 
their ideas before they put them into their writing. The ideas gathering help them a lot in organizing their thought in their writing. When they start gather ideas they think of anything related to the topics freely, then in the end they select the most appropriate ones and put them into the right order into their writing. The sources of information can be from any authentic materials such as magazine articles, advertisement, newspaper articles, etc. These authentic materials give them models of writing and also resource of information of what they are about to write for their writing assignments. The combination of reading to writing is like the combination of receiving and then drawing what they have received through reading to be drawn into their writing. Parpura and Pinkley (2000) present an advertisement about community center which offers different courses on a variety of skills. The learners can decide which course they want to study and then write a letter of inquiry to the community center. Finally, they give and receive feedback from their friend considering the following questions:

1. Does the letter include all the parts of a formal letter of inquiry?

2. Is it clear what the writer is asking for?

3. Are the ideas ordered in a logical way?

4. Is the language accurate?

(Parpura and Pinkley, 2000:10)

Compared to the Audio Lingual Method (ALM), the Communicative Approach in Language Teaching (CALT) activities offers more materials which primarily focus on the appropriacy and clarity of content which is related to the meaning, while the ALM prioritizes structural accuracy or forms of the language. The characteristics of CALT materials in writing is that they commonly use authentic materials, such as newspaper or magazine articles, advertisement, letter, etc. These materials can put the learners in real situations that they may experience in the future interactions in English. Because they are intentionally selected based on the learners' needs, authentic materials can then motivate student. They can stimulate learners' interest by manipulating real life and natural examples of the target language being learned.

Abundant of materials are available today that manipulate real life materials, like newspaper headlines, book or movie reviews (Soars \& Soars, 1998: 36), letters (Nolasco, 1993: 38). All of those authentic materials can be the sources for students to help them writing. They are the real materials where the language is actually used in the real life. Having those materials is a great help for teachers and learners to know how the language is used in the real communication activities in the daily life. Form the advertisement for example, we can find any valuable sources of information about an event or anything. Looking at it helps learners to see how people advertise and inform others for a certain occasion or event or even an activity that a course is about to do, it gives information about what courses are available, how much the cost one needs to pay when enrolling for the course.

\section{Conclusions}

Writing is indeed a skill which needs a serious concern in learning a language. Fluency is important, but it is not merely one single point of learning a language. The accuracy as well as communicative ability is also of similar importance. Two different language learning approaches have proposed two different focus of learning. The Audio Lingual Method in 1960s, focuses more on forms or structure of a language where fluency id everything. It gives only a minor attention toward writing skill. Meanwhile, the other approach, Communicative Approach in Language Teaching in 1970s, focuses more on the communicative use of language in the real life activities. These two different approaches in teaching have actually enlighten the teaching of writing by combining two focuses of language learning; that is forms or structures as well as meaning or purpose. A lot of techniques have been proposed to ease 
the writing process, such as free-writing (Peter Elbow, 1973) clustering, cubing (journalistic questions (Nolasco, 1993), and brainstorming, to help learners gather their ideas to be organized and developed into their writing.

The two approaches, ALM and CALT have also proposed a lot of activities to promote writing skill to be better. The ALM has the controlled writing tasks, while CALT has the authentic materials as the trigger for learners to have more natural and real use of language in their writing tasks. To underline is that, the teacher indeed, has to be more responsive rather than authoritative (Murray, 1985). Teacher is to give suggestions not to give judgement on the learners writing; he assists the learners rather than tells what they have to do. Here, the learners are given freedom to write their ideas, once they have done some parts they can discuss with the teacher about their writing; and teacher is again, to give suggestion or hints to the learners based on what they have done.

\section{References}

Dennis, D.P., Wiebe, M. T., Amato, M. F. (2014), Learning to Develop Culturally Relevant Approach to 21st Century Instruction, Teaching/Writing: The Journal of Writing Teacher Education, 3(2).

Donovan, C. \& Smolkin, L. (2002) Children's Genre Knowledge: An Examination of K-5 Students Performance on Multiple Tasks Providing Differing Levels of Scaffolding. Reading Research Quarterly Newark. 37 (4), pp 428-465.

Elbow, P. (1973), Writing Without Teachers. London: Oxford University Press.

Gallo, J. \& Hermann, B.(2014), Transforming Writing Teachers: Two Professional Development Possibilities. Teaching/ Writing: The Journal of Writing Teacher Education, 3(2).
Murray, D.M (1985), A Writer Teaches Writing. Boston: Houghton Mifflin Company

Nation, P. (2009), Teaching ESL/EFL Reading and Writing. London: Routledge.

Nolasco, R.(1993), WOW! 2 Oxford: Oxford University Press.

Purpura, J. \& Pinkley, D. (2000), On Target 2. New York: Longman

Reid, B. (1993) 'But We're Doing it Already!' Exploring a Response to the Concept of Reflective Practice in Order to Improve its Facilitation, Nurse Education Today, 13: 305-309.

Soars, L \& Soars, J. (1998), Headway: Upper Intermediate, Student;s Book, Oxford: Oxford University Press. 